IZA DP No. 5525

Alcohol and Student Performance:

Estimating the Effect of Legal Access

Jason M. Lindo

Isaac D. Swensen

Glen R. Waddell

February 2011 


\title{
Alcohol and Student Performance: Estimating the Effect of Legal Access
}

\author{
Jason M. Lindo \\ University of Oregon \\ and IZA \\ Isaac D. Swensen \\ University of Oregon \\ Glen R. Waddell \\ University of Oregon \\ and IZA
}

\section{Discussion Paper No. 5525 \\ February 2011}

\author{
IZA \\ P.O. Box 7240 \\ 53072 Bonn \\ Germany \\ Phone: +49-228-3894-0 \\ Fax: +49-228-3894-180 \\ E-mail: iza@iza.org
}

Any opinions expressed here are those of the author(s) and not those of IZA. Research published in this series may include views on policy, but the institute itself takes no institutional policy positions.

The Institute for the Study of Labor (IZA) in Bonn is a local and virtual international research center and a place of communication between science, politics and business. IZA is an independent nonprofit organization supported by Deutsche Post Foundation. The center is associated with the University of Bonn and offers a stimulating research environment through its international network, workshops and conferences, data service, project support, research visits and doctoral program. IZA engages in (i) original and internationally competitive research in all fields of labor economics, (ii) development of policy concepts, and (iii) dissemination of research results and concepts to the interested public.

IZA Discussion Papers often represent preliminary work and are circulated to encourage discussion. Citation of such a paper should account for its provisional character. A revised version may be available directly from the author. 
IZA Discussion Paper No. 5525

February 2011

\section{ABSTRACT}

\section{Alcohol and Student Performance: Estimating the Effect of Legal Access ${ }^{*}$}

We consider the effect of legal access to alcohol, which is known to increase drinking behavior, on academic performance. We first estimate the effect using an RD design but argue that this approach is not well-suited to the research question in our setting. Our preferred approach instead exploits the longitudinal nature of the data, essentially identifying the effect by comparing a student's academic performance before and after turning 21 . We find that students' grades fall below their expected levels upon being able to drink legally, but by less than previously documented. We also show that there are effects on women and that the effects are persistent. The main results are robust to the inclusion of individual fixed effects, individual trends, and individual quadratics, in addition to other controls, that account for the expected evolution of performance as students make progress towards their degrees.

JEL Classification: I21, I18, K32

Keywords: alcohol, post-secondary education, minimum legal drinking age

Corresponding author:

Glen R. Waddell

Department of Economics

University of Oregon

Eugene, OR 97403-1285

USA

E-mail: waddell@uoregon.edu

\footnotetext{
* The authors thank Scott Carrell and Mark Hoekstra for beneficial comments. Any errors remain the responsibility of the authors.
} 


\section{Introduction}

A large literature links alcohol consumption to adverse health and social outcomes. In particular, quasi-experimental methods have been used to consider effects on mortality (Dee 1999; Carpenter 2004; Carpenter and Dobkin 2009), crime (Markowitz and Grossman 1998; Carpenter 2005a; Carpenter 2007; Carpenter and Dobkin 2010), sexual activity (Chesson, Harrison, and Kassler 2000; Rees and Argys 2001; Sen 2002; Rashad 2004; Carpenter 2005b; Waddell forthcoming), employment (Mullahy and Sindelar 1996; Terza 2002; Dave and Kaestner 2002; MacDonald 2004), and teenagers' educational outcomes (Cook and Moore 1993; Dee and Evans 2003; Chatterji and DeSimone 2006), among others. Given long-standing and persistent efforts to restrict access to alcohol, it is no surprise that this topic has received considerable attention from policy-motivated researchers. That being said, relatively little is known about the effect of legal access to alcohol on the academic performance of students in college, where binge drinking is often cited as a serious and growing problem (DeSimone 2007). That alcohol is associated with the acute outcomes listed above gives cause for concern that effects on student performance may be quite large.

In this paper, we assess the magnitude of the effect using two identification strategies, one which has been used elsewhere to address the research question and one which has not, both of which exploit variation induced by the federally mandated minimum legal drinking age (MLDA) in order to speak to the effect of alcohol consumption on student performance. ${ }^{1}$ The first identification strategy follows Carrell, Hoekstra, and West (2011) who exploit the sharp change in legality that occurs at age 21 in a regression discontinuity (RD) framework, also to estimate effects on student performance. While it is relatively straightforward to use an RD design to estimate effects of turning 21 on crime or traffic accidents, as in Carpenter and Dobkin's works, it is less straightforward as an approach to estimating effects on academic outcomes since they are not measured frequently. For this reason, this RD approach uses

\footnotetext{
${ }^{1}$ Carpenter and Dobkin (2009) document that legal access does have a significant impact on drinking behavior despite the fact that individuals drink (illegally) prior to turning 21.
} 
age from 21 at the end of the academic term as the running variable. Thus, the RD design estimates the effect of legal access to alcohol for students who obtain access near the end of the academic term. In the limit, the thought experiment compares the performance of students who turn 21 the day before their final exam to the performance of students who turn 21 on the day of their final exam. The resulting estimates can therefore be characterized as measuring a local average treatment effect (LATE) which may have limited external validity.

Our second and preferred identification strategy overcomes this limitation by making use of the longitudinal nature of the data. In particular, we essentially identify the effect of legal access to alcohol by comparing a student's post- 21 academic performance to his own pre-21 academic performance. Implicitly arguing that the best counterfactual for a student's post-21 performance is his own performance prior to turning 21 , we estimate models that include individual fixed effects as well as models that include individual linear and quadratic trends. As such, our specifications are best thought of as considering the extent to which the average student's performance diverges from its trend after he gains legal access to alcohol. In addition, our regressions include fixed effects for the number of accumulated credits to account for the possibility that students may systematically improve, "slack off," or take easier classes as they progress towards degree completion. As in the first approach, we use a student's course performance relative to their classmates' as our outcome variable, which will also serve to control for selection into courses. ${ }^{2}$

The data and institutional setting that we consider, transcript-level data from undergraduates at the University of Oregon, allow us to make several additional contributions to the literature. One of the unique features of Carrell, Hoekstra, and West's (2011) study using data from the U.S. Air Force Academy is that underage drinking prohibition is taken extremely seriously there - much more so than in other institutional settings in which en-

\footnotetext{
${ }^{2}$ In related studies, Williams, Powell, Wechsler (2003) and Powell, Williams, and Wechsler (2004) consider the effect of alcohol consumption on college GPAs using data from the Harvard School of Public Health's College Alcohol Study. These studies involve cross-institution comparisons of student GPAs, with measures of alcohol costs serving as an instrument for drinking intensity among those who drink. Kremer and Levy (2008) consider a different-but-related question, exploiting the random assignment of roommates at a large state university in order to identify the effect of having a roommate who drinks.
} 
forcement is more lax and punishment less severe. ${ }^{3}$ As such, assuming Air Force Academy students are representative of the general student population, their RD estimates tell us about the local average treatment effect of prohibition in environments in which enforcement and penalties are unusually strict. In contrast, our results are more likely to speak to the effect of minimum drinking age laws as they are conventionally enforced and, in turn, the effect of the increase in drinking behavior that is typically associated with legal access to alcohol (Carpenter and Dobkin 2009). As we describe in the next section, the University of Oregon is also more representative of U.S. institutions, which we anticipate leading to improved external validity. Further, our data include over four times the number of observations used in this earlier research, and approximately ten times the number of females which allows a more precise consideration of heterogeneity across gender.

The results from our preferred approach indicate that students' grades fall below their expected levels by approximately 0.03 standard deviations upon being able to drink legally, a modest amount compared to the 0.06 to 0.13 standard-deviation effect estimated in earlier research. The effect is statistically significant, manifests in the term a student turns 21 , is not strongly related to when within the relevant quarter a student has their 21st birthday, and persists into later academic terms. In addition, we find that effects are concentrated among female students, "low ability" students, and those most likely to be from disadvantaged backgrounds.

We also estimate the effect using the RD approach described above but identify even larger effects of turning 20 near the end of the academic term than of turning 21 , which we interpret as evidence that there is a large birthday effect. This casts doubt on the usefulness of the RD approach in our setting. ${ }^{4}$

The rest of this paper is organized as follows. Section 2 discusses the data used in

\footnotetext{
${ }^{3}$ Carrell, Hoekstra, and West (2011) highlight this feature, pointing to the fact that that two incidents of underage drinking at the Air Force Academy result in expulsion and some single incidents, such as driving under the influence, also result in expulsion.

${ }^{4}$ Note that Carrell, Hoekstra, and West (2011) do not find evidence of birthday effects at the U.S. Air Force Academy.
} 
this analysis as well as the representative nature of the University of Oregon campus. In Section 3 we present an RD strategy and discuss the resulting estimates. Section 4 presents our preferred longitudinal approach and discusses our main empirical findings. Section 5 concludes and discusses the implications of our results.

\section{Data}

In this paper, we use administrative student-course level data from the University of Oregon, spanning winter 1998 through winter 2007. We focus on performance during the fall, winter, and spring terms. Because our identification strategies use variation provided by the federal MLDA law, we limit our sample to those undergraduate students who were enrolled in school the term of their 21st birthday or the term just prior to their 21st birthday. ${ }^{5}$ The resulting sample consists of 16,585 students contributing 568,288 total observations.

As one contribution of this paper is to provide insight into the effects of MLDA laws in a "typical-college setting," Table 1 compares characteristics of students at the University of Oregon to those at other U.S. public-four-year institutions. While Column 1 provides summary statistics based on our sample, Column 2 considers a more comprehensive set of characteristics based on data from the Integrated Postsecondary Education Data System (IPEDS). Similarly, Column 3 shows statistics on other public-four-year institutions, also using data from IPEDS. ${ }^{6}$

Table 1 largely supports that the University of Oregon provides a representative-college setting. While it is twice the size and has higher admission rates than the average publicfour-year institution, it is similar in terms of enrollment rates and in the ability of enrolled students as measured by SAT scores. It is also very similar to the average college in terms

\footnotetext{
${ }^{5}$ This includes students who experienced their 21st birthday, or the term just prior to their 21st birthday in the fall, winter, spring, or summer term.

${ }^{6}$ In comparing across institutions we have used variables that provide a snapshot of school admissions and graduation rates, general academic standards, undergraduate student demographics, and student financial costs and aid. The statistics reported in columns 2 and 3 are based primarily on the 2003-2004 academic year, which is close to the median year for our data.
} 
of costs and financial aid. Like most other institutions, the University of Oregon is over half female and predominately white, although at seventy-five percent it has a larger share of white students than average.

In contrast, the U.S. Air Force Academy, the only other institution where our research question has been previously addressed, offers a relatively unique setting. In addition to being highly selective, it is very different from most schools in terms its students' objectives. In particular, all students at the Air Force Academy are given full scholarships but are expected to serve a five-year commitment as a commissioned officer in the U.S. Air Force following graduation. Moreover, females comprise only eighteen percent of its student body, which stands in stark contrast to the nation-wide average of fifty-five percent. As mentioned in the introduction, it is also important to note that the Air Force Academy is an outlier in strongly enforcing the MLDA law. That students at the Air Force Academy are such a select group from the distribution of all students, in both ability and preferences, and that they are in an environment that is unusually strict with respect to underage drinking, gives cause for concern about the external validity of earlier estimates and highlights the importance of considering the research question in different contexts.

\section{$3 \quad$ RD Analysis}

\subsection{Empirical Strategy}

In this section, we estimate the effect of having had one's 21st birthday before the end of the academic term on academic performance using the following regression equation:

$$
G_{i j t}=\alpha_{0}+\alpha_{1} 1\left\{A G E_{i t} \geq 0\right\}+f\left(A G E_{i t}\right)+\epsilon_{i j t}
$$

where $G_{i j t}$ is the normalized grade for student $i$ in class $j$ in term $t . A G E_{i t}$ is the student's age at the end of the term in days, centered on 21 years. For example, in the comparison 
of means as estimates approach the treatment threshold from each side, a bandwidth of 90 days would put weight on all students who had their 21st birthday in the range 90 days prior to the end of the term (i.e., $A G E=90$ ) through 90 days after the end of the term (i.e., $A G E=-90)$. Lastly, $f\left(A G E_{i t}\right)$ controls for a student's age at the end of the term in a flexible manner. In practice, we estimate models that do not control for age at the end of the term, models that control for age at the end of the term with a linear specification flexible on each side of the cutoff, and models that control for age at the end of the term with a quadratic specification flexible on each side of the cutoff, and consider bandwidths between 20 days and 240 days.

It is important to note that this identification strategy departs from the usual RD exercise. Typically, we observe — or know as a result of institutional details — the extent to which the treatment of interest jumps on the "treatment side" of the threshold. For example, in DiNardo and Lee's (2004) unionization study, all elections with union support greater than fifty percent lead to unionization while elections with less support do not. Similarly, in Angrist and Lavy's (1999) class-size study, we observe class-size reductions above multiples of forty enrolled students. Our example is similar in the sense that all students on the "treatment side" of the threshold have had the opportunity to drink alcohol legally prior to the conclusion of the academic term. However, because the underlying first-stage effect on alcohol consumption is unknown, the magnitude of any estimated effect will be somewhat difficult to interpret. Even though we know that drinking tends to increase when one turns 21 (Carpenter and Dobkin 2009), we do not know to what extent this holds true for students who turn 21 near the end of an academic term, which this identification strategy pre-supposes. As such, the comparison involved with this RD approach is informative about the effect of drinking on college performance but its "local" nature (close to 21 and close to the end of the term) introduces additional interpretive challenges. ${ }^{7}$

\footnotetext{
${ }^{7}$ We note that all RD-based studies that consider the effect of being able to drink legally are local in the first (close to 21) sense but that the second sense is specific to this application, driven by the fact that outcomes are not measured daily.
} 
In the absence of estimated effects on drinking behavior, the results are appropriately characterized as intent-to-treat effects, measuring the reduced-form effect of the minimum drinking age law which is certainly of interest in itself. However, that the RD design only provides an estimate of a very local intent-to-treat effect, corresponding to students gaining legal access to alcohol at the end of the academic term, remains a disadvantage of this approach, something that we improve on with the identification strategy presented in the next section where we exploit the longitudinal nature of the data.

\subsection{Results}

Table 2 presents RD-based estimates of the effect of legal access to alcohol at the end of a term on academic performance. Across the fourteen columns, the table shows estimates based on a wide range of bandwidths and functional form choices. While Panel A reports unadjusted estimates, Panel B controls for course-by-quarter-by-year fixed effects, quarter-by-year-atthe-university fixed effects, birth-year fixed effects, accumulated-credits fixed effects, gender, math and verbal SAT scores, high-school GPA, and indicator variables for university athletes, private high school attendance, race and ethnicity. ${ }^{8}$

Overall, the set of results in Table 2 provides evidence that turning 21 before a quarter ends has a negative impact on a student's grades. While the point estimates vary somewhat from specification to specification, they are routinely negative and usually suggest that students who turn 21 prior to the end of the quarter score 0.02 to 0.04 standard deviations lower than those who turn 21 after the quarter ends.

As a robustness check, Table 3 reports the results from a similar exercise but instead considers the effect of turning 20 before a quarter ends. These results closely mirror those in Table 2. The graphical analysis shown in Figure A1 in the appendix also reveals this to be the case. As a whole, these results cast doubt on the usefulness of the RD-based identification strategy in our setting. In particular, these results suggest that there is a "twentieth birthday

\footnotetext{
${ }^{8}$ Race and ethnicity controls consists of a set of indicator variables for being black, Hispanic, or Asian.
} 
effect" which raises the concern that there also might be a "21st birthday effect" that cannot be separated from the effect of gaining legal access to alcohol near the end of the term. ${ }^{9}$

\section{Longitudinal Analysis}

In this section, we use our preferred approach to estimate the effects of legal access to alcohol which focuses on within-student variation over time. We begin our analysis by estimating the following regression:

$$
G_{i j t}=\theta A G E 21_{i t}+\beta X_{i j t}+\alpha_{i}+u_{i j t}
$$

where $G_{i j t}$ is the normalized grade for student $i$ in class $j$ in term $t, A G E 21_{i t}$ is an indicator variable that takes a value of one if the student could drink legally at any time during term $t$ and zero otherwise, $X_{i j t}$ can include term- or class-varying individual characteristics, $\alpha_{i}$ are a set of individual fixed effects, and $u_{i j t}$ is a random error term. In practice, we always include "experience controls" in $X_{i j t}$, i.e., fixed effects for the number of accumulated credits (in intervals of four) and fixed effects for the number of years a student has been at the university, to control for grade changes that are expected as a student progresses towards his degree. ${ }^{10}$ As such, the estimation strategy essentially compares a student's grades after turning 21 to what would be expected based on his average prior performance and accumulated experience. ${ }^{11}$

In order to obtain a better counterfactual for a student's expected post-21 performance,

\footnotetext{
${ }^{9}$ In the appendix we show that a similar exercise considering the effect of turning 22 before a quarter ends does not indicate the presence of a birthday effect. Carrell, Hoekstra, and West (2011) conduct a similar analysis and find no evidence of 20th or 22nd birthday effects at the U.S. Air Force Academy. In an attempt to separate the short-term birthday effect from that of a potentially-persistent effect of legal access to alcohol we have also explored the use of a donut RD approach (Carpenter and Dobkin 2009; Barreca, Guldi, Lindo, and Waddell 2010; Barreca, Guldi, Lindo and Waddell, forthcoming). In particular, we have conducted a similar analysis after dropping observations $1,2,3,10$, and 15 days to either side of the cutoff. This analysis continued to show similar estimates when considering the effect of turning 20 and 21.

${ }^{10}$ For example, these variables will control for phenomena such as "senioritis."

${ }^{11}$ We also estimate models that control for course characteristics.
} 
we also estimate models that include individual specific trends,

$$
G_{i j t}=\theta A G E 21_{i t}+\beta X_{i j t}+\alpha_{i}+\omega_{i} t+u_{i j t}
$$

and individual specific quadratics,

$$
G_{i j t}=\theta A G E 21_{i t}+\beta X_{i j t}+\alpha_{i}+\omega_{i} t+\theta_{i} t^{2}+u_{i j t}
$$

Estimates based on these models essentially compare a student's grades after turning 21 to what would be expected based on the trajectory of his prior performance and his accumulated experience. $^{12}$

\subsection{Main Results}

Table 4 presents our main results, utilizing the longitudinal nature of the data to estimate the effect of legal access to alcohol on a student's grades. Column 1 shows estimates based on a model that includes student fixed effects and controls for a student's accumulated credits and number of years at the university (Equation 2). The point estimate, statistically significant at the one-percent level, indicates that a student's course-normalized grades fall by 0.032 standard deviations after they gain legal access to alcohol relative to what we would expect based on their prior performance and accumulated experience. The estimated effect is similar in Column 2 in which we add controls for subject-by-level fixed effects and term fixed effects. ${ }^{13}$ The remaining columns of Table 4 add individual-specific trends and then individual-specific quadratics to the regression model. The estimates based on these moreflexible models are slightly smaller but remain statistically significant at the one-percent

\footnotetext{
${ }^{12}$ Note that $t=1$ in a student's first term at the university, $t=2$ in a student's second term at the university, etc.

${ }^{13}$ For example, subjects correspond to economics, english, and mathematics. Levels correspond to either 100-, 200-, 300-, or 400-level classes. As summer-terms are not considered as part of our analysis, terms are fall, winter, and spring.
} 
level. ${ }^{14}$

\subsection{Treatment-Effect Dynamics}

In order to consider the dynamic effect of being able to drink legally, Table 5 replaces the post-21 indicator variable with a set of indicator variables corresponding to the number of terms preceding or following the term in which a student gains legal access to alcohol. In particular, we include separate indicator variables for turning 21 two or one term in the future, for the term in which the individual turns 21 , and then for having turned 21 one through six-or-more terms ago. The omitted category, essential for identifying individual fixed effects and trends, is being three or more terms prior to turning $21 .{ }^{15}$

It is worth noting that in Column 1 the estimated coefficient on the indicator for being one term prior to turning 21 is statistically significant, raising a concern that the model only including individual fixed effects might be misspecified or that there might be an effect of having friends who are beginning to turn 21. In contrast, however, there is no such evidence when individual trends or individual quadratics are included in the model (columns 2 and 3). In particular, there is no evidence of a pre-21 dip in performance in the more flexible models.

In the model with individual-specific trends, the point estimates indicate that grades fall 0.029 to 0.039 standard deviations below their expected levels in the term a student turns 21 , suggesting an immediate negative effect of legal access to alcohol on academic performance. The estimated coefficients corresponding to subsequent terms remain negative but tend to be smaller which suggests that there is some recovery but that the effect persists - the set of coefficients corresponding to effects in terms after an individual has their 21st birthday are jointly significant (with p-values of 0.000, 0.044, and 0.099 across columns 1 through

\footnotetext{
${ }^{14}$ We have also considered effects on students' best and worst course performance in each quarter. These results are very similar to the average effects, suggesting that effect is well-characterized by a mean shift.

${ }^{15}$ Note that although summer terms do not contribute to out analysis, such terms are considered in defining the term-based proximity to the term in which a student turns 21 . As such, when the "turned 21 four terms ago" indicator variable is equal to one we are considering an individual in the term he turns 22 .
} 
3). Although the estimate is somewhat imprecise, the coefficient on having turned 21 four terms ago seems particularly large which is suggestive of a 22nd-birthday effect. In results not shown but available upon request, we have included indicators for being three and four terms prior to turning 21 in order to examine the possibility of a twentieth-birthday effect this analysis produced no evidence of a such an effect in contrast to the RD-based analysis discussed above.

Table 6 further explores the dynamic effects of legal access to alcohol, turning attention to the timing of a student's 21st birthday during the quarter. In particular, this table replaces the indicator for turning 21 in the current term with an indicator for turning 21 in weeks 10-11 of the current quarter, weeks $7-9$ of the current quarter, 4-6 weeks of the current quarter, and weeks 1-3 of the current quarter. In large part, it is not clear what pattern of estimates we would expect this analysis to reveal. On one hand, the effects might be most severe for students gaining legal access at the beginning of the term since they will be exposed for a longer time, potentially impairing their learning throughout the entire quarter. On the other hand, an early-term birthday may allow students to "get it out of their system" early in the quarter, leading to greater focus near the end of the term when studying may be most productive.

The set of estimates in Table 6 points to significant effects of gaining legal access to alcohol at any time during a given quarter. However, we note that the estimated effect of a being able to drink legally as of the tenth or eleventh week of a given quarter is relatively small, which is what we would expect since a share of these birthdays will have taken place after students have already completed their final exams. ${ }^{16}$ The point estimates indicate that turning 21 in weeks $7-9$ reduce current-term grades by 0.02 to 0.04 standard deviations, turning 21 in weeks $4-6$ reduce grades by 0.04 to 0.05 standard deviations, and turning 21 in weeks $1-3$ reduces grades by 0.03 to 0.04 standard deviations. As such, it appears as if the most severe effects arise for students who are able to start drinking legally midway through

\footnotetext{
${ }^{16}$ We do not have information on the exact date on which specific courses held final exams.
} 
the quarter which does not provide clear evidence against either of the hypotheses described above. Further, the standard errors are too large to reject that the effect is the same for students gaining legal access to alcohol at different times during the quarter.

\subsection{Treatment Effect Heterogeneity}

Table 7 stratifies the estimates by student gender and ability, where "high ability" students are those with cumulative SAT scores above the sample median score of 1120 and "low ability" students are those with cumulative SAT scores at or below the sample median. Although this table focuses on results based on a model with individual trends, Table A2 in the appendix demonstrates that estimates are similar when individual quadratics are included.

Columns 1 and 2 reveal that the effect of being able to drink legally is greater for females than for males, reducing grades by approximately 0.04 standard deviations for females and 0.02 standard deviations for males. Columns 3 and 4 reveal that there is also heterogeneity across ability. The point estimates indicate that the effect on low-ability students is approximately 0.04 standard deviations whereas the effect is smaller and only statistically significant at the ten-percent level for the high-ability group.

Columns 5 through 8 separately consider the effects for low-ability males, high-ability males, low-ability females, and high-ability females. These estimates reveal that the effect on males is driven primarily by low-ability males, whose grades fall 0.04 standard deviations below their expected level after they gain legal access to alcohol. In contrast, there appears to be no effect on high-ability males. On the other hand, our point estimates suggest that there are negative effects for both high- and low-ability females although the estimated effects are greatest for low-ability females.

Table 7 stratifies the estimates by financial-aid eligibility and gender for those students

who submitted a Free Application for Federal Student Aid (FAFSA), approximately seventy percent of the full sample. Column 1 shows that the estimated effect for this sample of 
students is very similar to the estimated effects based on the full sample. Columns 3 and 4 show that legal access to alcohol has significant effects on students with financial aid eligibility above the sample median and those with eligibility below the median, although the estimated effect is larger for those with greater eligibility who are more likely to be from disadvantaged backgrounds. The remaining columns suggest that this differential exists for both male and female students.

\section{Discussion and Conclusion}

As a whole, the preceding analysis suggests that legal access to alcohol does affect student performance, reducing grades by approximately 0.03 standard deviations. To put this magnitude into context, it is equivalent to causing a student to perform as if his SAT score were 20 points lower.

In addition to what was discussed in the introduction, one of the benefits of our longitudinal analysis is its ability to speak to the extent to which the effect is sensitive to the timing of a student's 21st birthday within the term. The estimates suggest that the effect is just as great for those turning 21 at the end of a term as it is those turning 21 at the beginning of the term. As such, we are confident in concluding that the effect we identify is smaller than Carrell, Hoekstra, and West (2011) who find that gaining legal access at the end of the academic term reduces grades by approximately 0.10 standard deviations. This difference is perhaps surprising when one considers that the U.S. Air Force Academy is more selective and has a much larger fraction of men than the University of Oregon, where we find no evidence of an effect among high-ability males. In addition, in contrast to previous literature, we identify a significant effect on the performance of females.

While these effects are small, and potentially resulting from a rational calculation in which students trade off higher grades in exchange for perceived-higher-quality leisure, our results do suggest that it may be important to consider other longer-term outcomes. In particular, 
given that our results suggest that the effect is persistent, there might be important impacts on subsequent labor-market outcomes. The literature's best evidence linking alcohol and labor market outcomes in the U.S. uses state-level aggregates (Dave and Kaestner 2001), survey data from the 1988 National Health Interview Survey (Mullahy and Sindelar 1996; Terza 2002), and from the National Longitudinal Survey of Youth (Renna 2009), where power is a challenge to identification. We see this as an important area for future research with a great need for improved sources of data. 


\section{References}

Angrist, J.D., and V. Lavy. 1999. "Using Maimonides' Rule to Estimate the Effect of Class Size on Scholastic Achievement," Quarterly Journal of Economics, 114(2): 533-575.

Barreca, A., M. Guldi, J.M. Lindo, and G.R. Waddell. forthcoming. "Saving Babies? Revisiting the Effect of Very Low Birth Weight Classification," Quarterly Journal of Economics.

Barreca, A., M. Guldi, J.M. Lindo, and G.R. Waddell. 2010. "Running and Jumping Variables in Regression Discontinuity Designs," IZA Discussion Paper No. 5106.

Carpenter, C. 2004. "Heavy Alcohol Use and Youth Suicide: Evidence from Tougher Drunk Driving Laws," Journal of Policy Analysis and Management, 23(4): 831-842.

Carpenter, C. 2005a. "Heavy Alcohol Use and the Commission of Nuisance Crime: Evidence from Underage Drunk Driving Laws," American Economic Review, 95(2): 267-272.

Carpenter, C. 2005b. "Youth Alcohol Use and Risky Sexual Behavior: Evidence from Underage Drunk Driving Laws," Journal of Health Economics, 24(3): 613-628.

Carpenter, C., and C. Dobkin. 2009. "The Effect of Alcohol Consumption on Mortality: Regression Discontinuity Evidence from the Minimum Drinking Age," American Economic Journal: Applied Economics, 1(1): 164.

Carpenter, C., and C. Dobkin. 2010. "The Drinking Age, Alcohol Consumption, and Crime," working paper.

Carpenter, C. 2007. "Heavy Alcohol Use and Crime: Evidence from Underage DrunkDriving Laws." Journal of Law and Economics, 50: 539-781.

Carrell, S.E., M. Hoekstra, and J.E. West. 2011. "Does Drinking Impair College Performance? Evidence from a Regression Discontinuity Approach," Journal of Public Economics. 
Chatterji, P., and J.S. DeSimone. 2006. "High School Alcohol Use and Young Adult Labor Market Outcomes," NBER Working Paper.

Chesson, H., P. Harrison, and W.J. Kassler. 2000. "Sex Under the Influence: The Effect of Alcohol Policy on Sexually Transmitted Disease Rates in the United States," Journal of Law and Economics, 43(1): 215-238.

Cook, P.J., and M.J. Moore. 1993. "Drinking and Schooling," Journal of Health Economics, 12(4): 411.

Dave, D., and R. Kaestner. 2002. "Alcohol Taxes and Labor Market Outcomes," Journal of Health Economics, 21(3): 357-371.

Dee, T.S. 1999. "State Alcohol Policies, Teen Drinking and Traffic Fatalities," Journal of Public Economics, 72(2): 289-315.

Dee, T.S., and W.N. Evans. 2003. "Teen Drinking and Educational Attainment: Evidence from Two-Sample Instrumental Variables Estimates," Journal of Labor Economics, 21(1).

DeSimone, J. 2007. "Fraternity Membership and Binge Drinking," Journal of Health Economics, 26(5): 950-967.

DiNardo, J., and D.S. Lee. 2004. "Economic Impacts of New Unionization on Private Sector Employers: 1984-2001," Quarterly Journal of Economics, 119(4): 1383-1441.

Kremer, M., and D. Levy. 2008. "Peer Effects and Alcohol Use Among College Students," The Journal of Economic Perspectives, 22(3): 189-3A.

MacDonald, Z., and M.A. Shields. 2004. "Does Problem Drinking Affect Employment? Evidence from England," Health Economics, 13(2): 139-155.

Markowitz, S., and M. Grossman. 1998. "Alcohol Regulation and Domestic Violence Towards Children," Contemporary Economic Policy, 16(3): 309-320. 
Mullahy, J., and J. Sindelar. 1996. "Employment, Unemployment, and Problem Drinking," Journal of Health Economics, 15(4): 409-434.

Powell, L.M., J. Williams, and H. Wechsler. 2004. "Study Habits and the Level of Alcohol Use Among College Students," Education Economics, 12(2): 135-149.

Rashad, I., and R. Kaestner. 2004. "Teenage Sex, Drugs and Alcohol Use: Problems Identifying the Cause of Risky Behaviors," Journal of Health Economics, 23(3): 493-503.

Renna, F. 2008. "Alcohol Abuse, Alcoholism, and Labor Market Outcomes: Looking for the Missing Link," Industrial and Labor Relations Review, 62(1): 92-103.

Rees, D.I., L.M. Argys, and S.L. Averett. 2001. "New Evidence on the Relationship Between Substance Use and Adolescent Sexual Behavior," Journal of Health Economics, 20(5): 835-845.

Sen, B. 2002. "Does Alcohol-Use Increase the Risk of Sexual Intercourse Among Adolescents? Evidence from the NLSY97," Journal of Health Economics, 21(6): 1085-1093.

Terza, J.V. 2002. "Alcohol Abuse and Employment: A Second Look," Journal of Applied Econometrics, 17(4): 393-404.

Waddell, G. R. forthcoming. "Gender and the Influence of Peer Alcohol Consumption on Adolescent Sexual Activity," Economic Inquiry.

Williams, J., L.M. Powell, and H. Wechsler. 2003. "Does Alcohol Consumption Reduce Human Capital Accumulation? Evidence from the College Alcohol Study," Applied Economics, 35(10): 1227-1239. 
Table 1

Summary Statistics

\begin{tabular}{|c|c|c|c|}
\hline & $\begin{array}{r}\text { Oregon } \\
\text { (Sample) } \\
\end{array}$ & $\begin{array}{c}\text { Oregon } \\
\text { (IPEDS) } \\
\end{array}$ & $\begin{array}{l}\text { Four-year Public } \\
\text { U.S. Institutions } \\
\quad \text { (IPEDS) } \\
\end{array}$ \\
\hline SAT I Verbal 25th percentile score, incoming students & 500 & 490 & 464 \\
\hline SAT I Verbal 75 th percentile score, incoming students & 620 & 610 & 568 \\
\hline SAT I Math 25th percentile score, incoming students & 500 & 500 & 472 \\
\hline SAT I Math 75th percentile score, incoming students & 620 & 610 & 578 \\
\hline Number of undergraduates & 16,585 & 15,983 & 8,674 \\
\hline Fraction female & 0.55 & 0.53 & 0.55 \\
\hline Fraction white & 0.79 & 0.75 & 0.67 \\
\hline Fraction black & 0.02 & 0.02 & 0.11 \\
\hline Fraction Hispanic & 0.03 & 0.03 & 0.08 \\
\hline Fraction Asian & 0.15 & 0.12 & 0.11 \\
\hline Total price for in-state students living on campus & & 14,734 & 13,272 \\
\hline Total price out-of-state students living on campus & & 26,170 & 20,022 \\
\hline Fraction receiving any financial aid & & 0.70 & 0.75 \\
\hline Fraction receiving federal-grant aid & & 0.18 & 0.34 \\
\hline Fraction receiving student-loan aid & & 0.40 & 0.45 \\
\hline
\end{tabular}

Notes: Data used in the first columns consists of University of Oregon undergraduates from 1998 through 2007. Financial aid statistics shown in the last two columns are calculated using 2004 IPEDS data, while all other statistics in the same columns are calculated using 2003 IPEDS data. The number institutions used to calculate the means in the final column range 352 to 653 . 


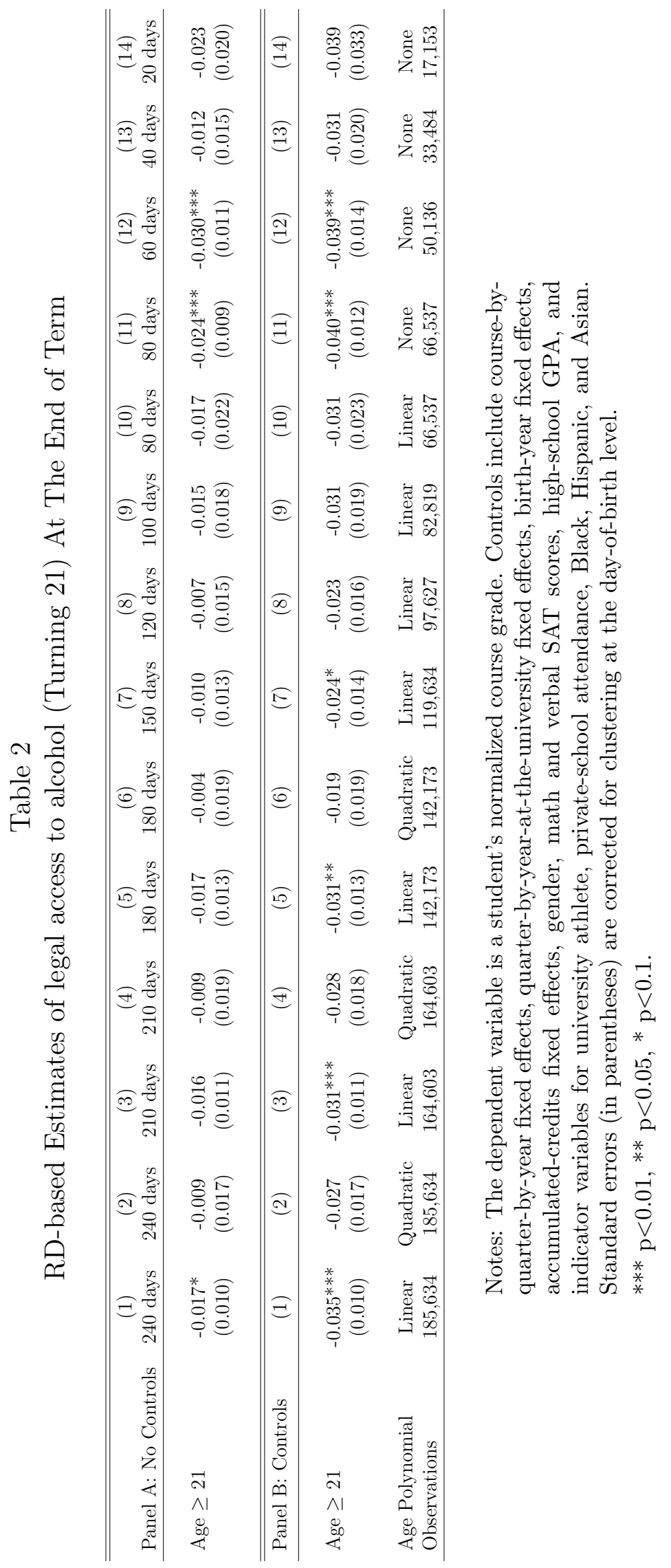




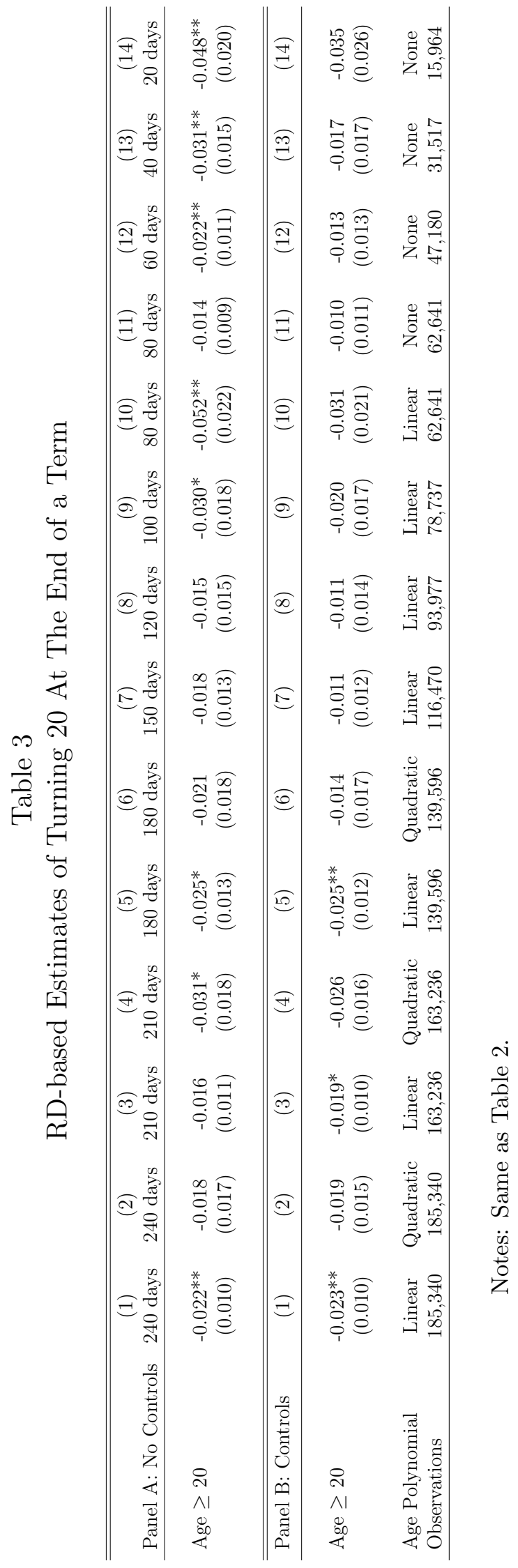


Table 4

Estimated Effect of Legal Access to Alcohol During a Term

\begin{tabular}{lcccccc}
\hline \hline & $(1)$ & $(2)$ & $(3)$ & $(4)$ & $(5)$ & $(6)$ \\
\hline \multirow{2}{*}{ Age $>21$ During Term } & & & & & & \\
& $-0.032^{* * *}$ & $-0.035^{* * *}$ & $-0.029^{* * *}$ & $-0.027^{* * *}$ & $-0.026^{* * *}$ & $-0.025^{* * *}$ \\
& $(0.006)$ & $(0.006)$ & $(0.006)$ & $(0.006)$ & $(0.006)$ & $(0.006)$ \\
Individual Fixed Effects & & & & & & \\
Individual Trends & yes & yes & yes & yes & yes & yes \\
Individual Quadratics & no & no & yes & yes & yes & yes \\
Experience Controls & no & no & no & no & yes & yes \\
Subject/Level/Term Controls & yes & yes & yes & yes & yes & yes \\
Number of Students & 16,585 & 16,585 & 16,585 & 16,585 & 16,585 & yes \\
Observations & 561,576 & 561,576 & 561,576 & 561,576 & 561,576 & 561,576 \\
\hline
\end{tabular}

Notes: The dependent variable is equal to the student's normalized course grade. Experience controls include accumulated-credits fixed effects and year-at-the-university fixed effects. Subject/Level/Term controls include subject-by-level fixed effects and term fixed effects. Standard errors (in parentheses) are corrected for clustering at the individual level.

$* * * \mathrm{p}<0.01,{ }^{* *} \mathrm{p}<0.05,{ }^{*} \mathrm{p}<0.1$. 
Table 5

Dynamic Effects of Legal Access to Alcohol During a Term

\begin{tabular}{lccc}
\hline \hline & $(1)$ & $(2)$ & $(3)$ \\
\hline Turns 21 in 2 terms & -0.005 & 0.000 & 0.002 \\
& $(0.006)$ & $(0.006)$ & $(0.006)$ \\
Turns 21 in 1 term & $-0.022^{* * *}$ & -0.010 & 0.003 \\
& $(0.007)$ & $(0.008)$ & $(0.009)$ \\
Term of 21st birthday & $-0.056^{* * *}$ & $-0.039^{* * *}$ & $-0.029^{* *}$ \\
& $(0.009)$ & $(0.010)$ & $(0.011)$ \\
Turned 21 1 term ago & $-0.050^{* * *}$ & $-0.029^{* *}$ & -0.016 \\
& $(0.010)$ & $(0.012)$ & $(0.015)$ \\
Turned 21 2 terms ago & $-0.054^{* * *}$ & $-0.029^{*}$ & -0.017 \\
& $(0.012)$ & $(0.015)$ & $(0.018)$ \\
Turned 21 3 terms ago & $-0.059^{* * *}$ & -0.027 & -0.015 \\
& $(0.013)$ & $(0.018)$ & $(0.022)$ \\
Turned 21 4 terms ago & $-0.084^{* * *}$ & $-0.043^{* *}$ & -0.035 \\
& $(0.015)$ & $(0.021)$ & $(0.027)$ \\
Turned 21 5 terms ago & $-0.071^{* * *}$ & -0.028 & -0.016 \\
& $(0.017)$ & $(0.024)$ & $(0.031)$ \\
Turned 21 6+ terms ago & $-0.097^{* * *}$ & -0.037 & -0.032 \\
& $(0.020)$ & $(0.030)$ & $(0.037)$ \\
& & & \\
Individual Fixed Effects & yes & yes & yes \\
Individual Trends & no & yes & yes \\
Individual Quadratics & no & no & yes \\
Experience Controls & yes & yes & yes \\
Subject/Level/Term Controls & yes & yes & yes \\
Number of Students & 16,585 & 16,585 & 16,585 \\
Observations & 561,576 & 561,576 & 561,576 \\
\hline
\end{tabular}

Notes: Same as Table 4. 
Table 6

Dynamic Effects of Legal Access to Alcohol Allowing Effect to Vary with Timing of Birthday

\begin{tabular}{|c|c|c|c|}
\hline & $(1)$ & $(2)$ & $(3)$ \\
\hline Turns 21 in 2 terms & $\begin{array}{l}-0.005 \\
(0.006)\end{array}$ & $\begin{array}{l}-0.000 \\
(0.006)\end{array}$ & $\begin{array}{c}0.002 \\
(0.006)\end{array}$ \\
\hline Turns 21 in 1 term & $\begin{array}{c}-0.022^{* * *} \\
(0.007)\end{array}$ & $\begin{array}{l}-0.010 \\
(0.008)\end{array}$ & $\begin{array}{c}0.003 \\
(0.009)\end{array}$ \\
\hline Term of 21st birthday, weeks 10-11 & $\begin{array}{c}-0.039 * * * \\
(0.015)\end{array}$ & $\begin{array}{r}-0.026^{*} \\
(0.015)\end{array}$ & $\begin{array}{l}-0.015 \\
(0.017)\end{array}$ \\
\hline Term of 21 st birthday, weeks $7-9$ & $\begin{array}{c}-0.051^{* * *} * \\
(0.012)\end{array}$ & $\begin{array}{c}-0.038 * * * \\
(0.013)\end{array}$ & $\begin{array}{r}-0.024^{*} \\
(0.015)\end{array}$ \\
\hline Term of 21st birthday, weeks $4-6$ & $\begin{array}{c}-0.069 * * * \\
(0.012)\end{array}$ & $\begin{array}{c}-0.052^{* * *} \\
(0.013)\end{array}$ & $\begin{array}{c}-0.044^{* * *} \\
(0.014)\end{array}$ \\
\hline Term of 21 st birthday, weeks $1-3$ & $\begin{array}{c}-0.058^{* * *} \\
(0.010)\end{array}$ & $\begin{array}{c}-0.036 \text { *** } \\
(0.011)\end{array}$ & $\begin{array}{c}-0.027^{* *} \\
(0.013)\end{array}$ \\
\hline Turned 211 term ago & $\begin{array}{c}-0.050 * * * \\
(0.010)\end{array}$ & $\begin{array}{c}-0.029^{* *} \\
(0.012)\end{array}$ & $\begin{array}{l}-0.016 \\
(0.015)\end{array}$ \\
\hline Turned 212 terms ago & $\begin{array}{c}-0.054^{* * *} \\
(0.012)\end{array}$ & $\begin{array}{c}-0.029^{*} \\
(0.015)\end{array}$ & $\begin{array}{l}-0.017 \\
(0.018)\end{array}$ \\
\hline Turned 213 terms ago & $\begin{array}{c}-0.059 * * * \\
(0.013)\end{array}$ & $\begin{array}{l}-0.027 \\
(0.018)\end{array}$ & $\begin{array}{l}-0.015 \\
(0.022)\end{array}$ \\
\hline Turned 214 terms ago & $\begin{array}{c}-0.084^{* * *} \\
(0.015)\end{array}$ & $\begin{array}{c}-0.043^{* *} \\
(0.021)\end{array}$ & $\begin{array}{l}-0.035 \\
(0.027)\end{array}$ \\
\hline Turned 215 terms ago & $\begin{array}{c}-0.071^{* * *} \\
(0.017)\end{array}$ & $\begin{array}{l}-0.028 \\
(0.024)\end{array}$ & $\begin{array}{l}-0.016 \\
(0.031)\end{array}$ \\
\hline Turned $216+$ terms ago & $\begin{array}{c}-0.097^{* * *} \\
(0.020)\end{array}$ & $\begin{array}{l}-0.037 \\
(0.030)\end{array}$ & $\begin{array}{l}-0.032 \\
(0.037)\end{array}$ \\
\hline Individual Fixed Effects & yes & yes & yes \\
\hline Individual Trends & no & yes & yes \\
\hline Individual Quadratics & no & no & yes \\
\hline Experience Controls & yes & yes & yes \\
\hline Subject/Level/Term Controls & yes & yes & yes \\
\hline Number of Students & 16,585 & 16,585 & 16,585 \\
\hline Observations & 561,576 & 561,576 & 561,576 \\
\hline
\end{tabular}

Notes: Same as Table 4. 
Table 7

Heterogeneity Across Gender and Ability

\begin{tabular}{|c|c|c|c|c|c|c|c|c|}
\hline $\begin{array}{l}\text { Gender: } \\
\text { Ability: }\end{array}$ & $\begin{array}{c}(1) \\
\text { Male } \\
\text { All } \\
\end{array}$ & $\begin{array}{c}(2) \\
\text { Female } \\
\text { All }\end{array}$ & $\begin{array}{c}(3) \\
\text { All } \\
\text { High }\end{array}$ & $\begin{array}{c}\text { (4) } \\
\text { All } \\
\text { Low }\end{array}$ & $\begin{array}{c}(5) \\
\text { Male } \\
\text { High }\end{array}$ & $\begin{array}{c}(6) \\
\text { Male } \\
\text { Low }\end{array}$ & $\begin{array}{c}(7) \\
\text { Female } \\
\text { High }\end{array}$ & $\begin{array}{c}(8) \\
\text { Female } \\
\text { Low }\end{array}$ \\
\hline Age $>21$ During Term & $\begin{array}{c}-0.022^{* *} \\
(0.009)\end{array}$ & $\begin{array}{c}-0.038^{* * *} \\
(0.007)\end{array}$ & $\begin{array}{c}-0.015^{*} \\
(0.008)\end{array}$ & $\begin{array}{c}-0.037^{* * *} \\
(0.008)\end{array}$ & $\begin{array}{c}-0.006 \\
(0.012)\end{array}$ & $\begin{array}{c}-0.038^{* * *} \\
(0.012)\end{array}$ & $\begin{array}{c}-0.030 * * * \\
(0.011)\end{array}$ & $\begin{array}{c}-0.044^{* * *} \\
(0.010)\end{array}$ \\
\hline Individual Fixed Effects & yes & yes & yes & yes & yes & yes & yes & yes \\
\hline Individual Trends & yes & yes & yes & yes & yes & yes & yes & yes \\
\hline Experience Controls & yes & yes & yes & yes & yes & yes & yes & yes \\
\hline Subject/Level/Term Controls & yes & yes & yes & yes & yes & yes & yes & yes \\
\hline Number of Students & 7,452 & 9,133 & 7,979 & 8,606 & 4,018 & 3,434 & 3,961 & 5,172 \\
\hline Observations & 254,412 & 307,164 & 275,424 & 286,152 & 139,495 & 114,917 & 135,929 & 171,235 \\
\hline
\end{tabular}

Notes: Same as Table 4. The high-ability group consists of students with SAT scores above the sample median (1120) while the low-ability group consists of those with SAT scores at or below the sample median. 
Table 8

Heterogeneity Across Gender and Financial Aid Eligibility

\begin{tabular}{lccccccc}
\hline \hline & $(1)$ & $(2)$ & $(3)$ & $(4)$ & $(5)$ & $(6)$ & $(7)$ \\
Gender: & All & All & All & Male & Male & Female & $\begin{array}{c}\text { Female } \\
\text { Below }\end{array}$ \\
Eligibility: & All & Above & Below & Above & Below & Above & Below \\
\hline & & & & & & & \\
Age $>21$ During Term & $-0.024^{* * *}$ & $-0.031^{* * *}$ & $-0.019^{* *}$ & -0.024 & -0.012 & $-0.040^{* * *}$ & $-0.031^{* *}$ \\
& $(0.007)$ & $(0.009)$ & $(0.009)$ & $(0.015)$ & $(0.014)$ & $(0.012)$ & $(0.012)$ \\
& & & & & & & \\
Individual Fixed Effects & yes & yes & yes & yes & yes & yes & yes \\
Individual Trends & yes & yes & yes & yes & yes & yes & yes \\
Experience Controls & yes & yes & yes & yes & yes & yes & yes \\
Subject/Level/Term Controls & yes & yes & yes & yes & yes & yes & yes \\
Number of Students & 11396 & 5705 & 5691 & 2378 & 2489 & 3327 & 3202 \\
Observations & 390,451 & 192,767 & 197,684 & 80,934 & 87,267 & 111,833 & 110,417 \\
\hline
\end{tabular}

Notes: Same as Table 4. The high-eligibility group consists of students with eligibility above the sample median while the low-eligibility group consists of those with eligibility below the sample median. 


\section{Appendix}

Figure A1

Graphical Analysis of RD-Based Estimates
Panel A

Estimated Effect of Turning 21 At End of Term

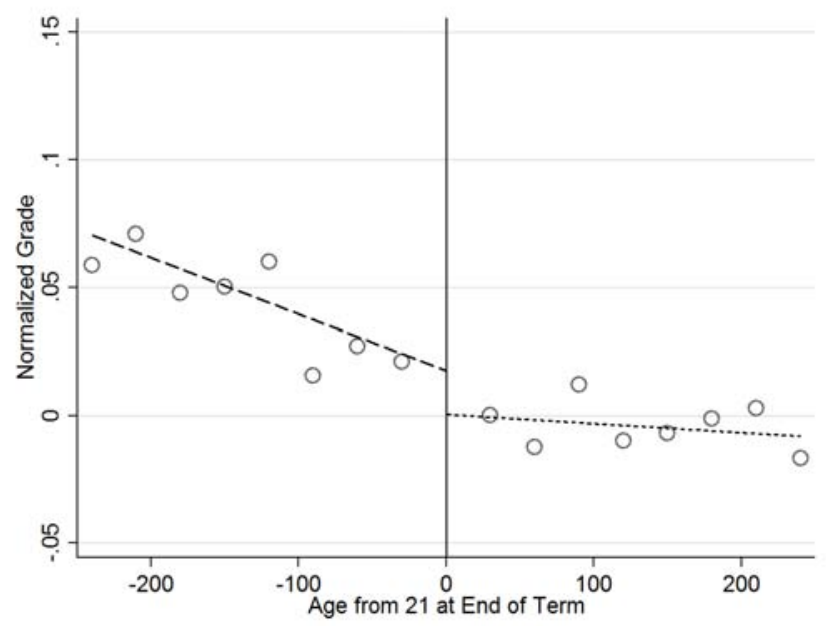

Panel B

Estimated Effect of Turning 20 At End of Term

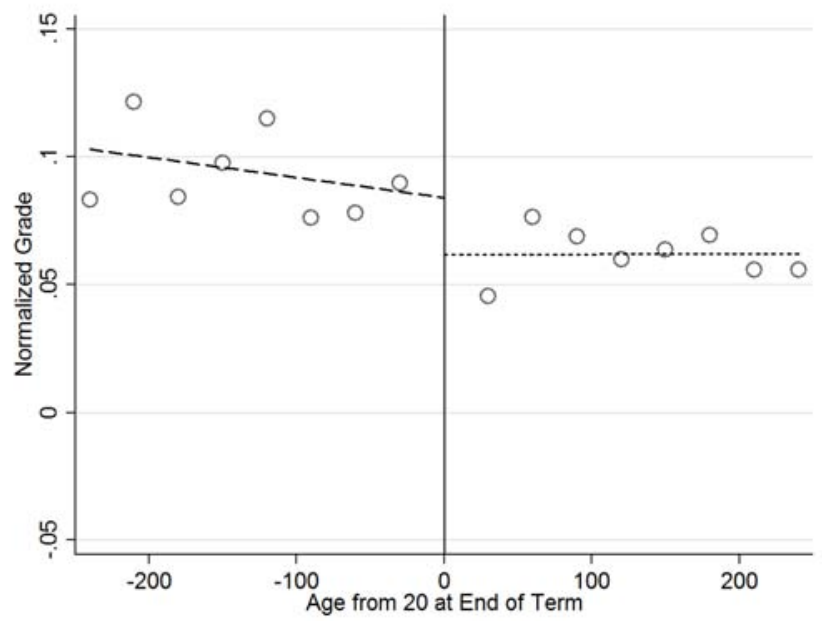

Notes: Each hollow circle corresponds to the mean within a thirty-day bin. The line is fitted using data 240 days on each side of the threshhold. 


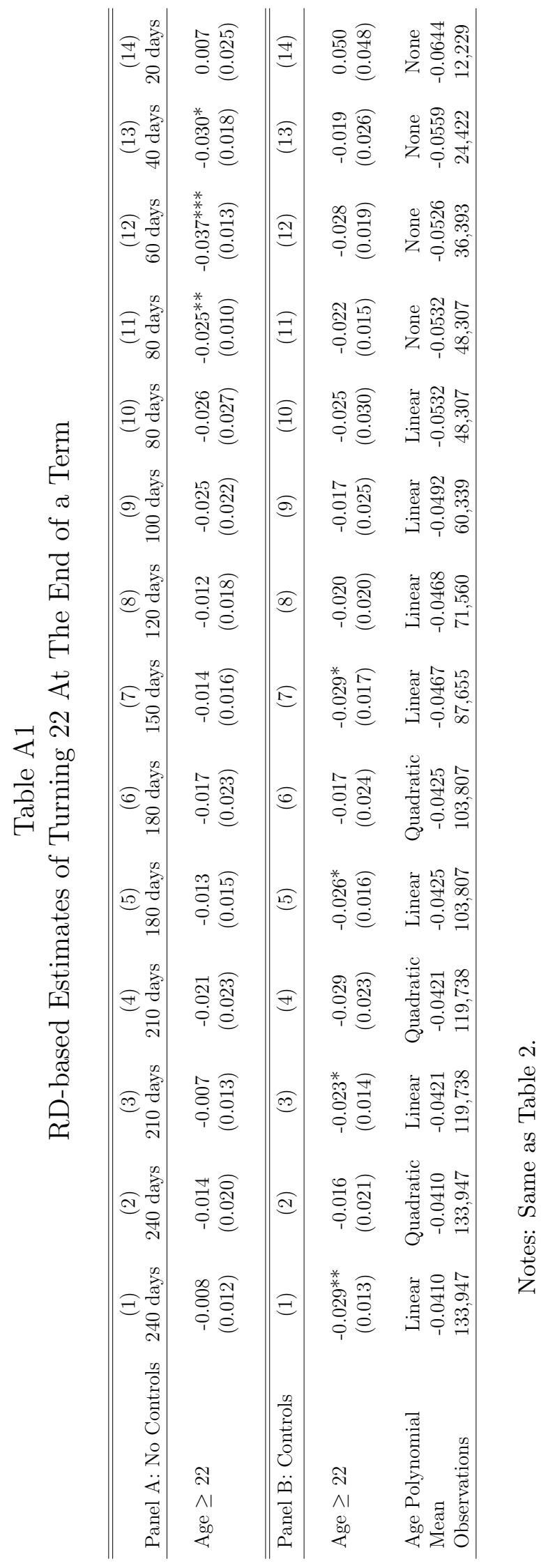


Table A2

Heterogeneity Across Gender and Ability

Controlling for Individual Quadratic Trends

\begin{tabular}{|c|c|c|c|c|c|c|c|c|}
\hline $\begin{array}{l}\text { Gender: } \\
\text { Ability: }\end{array}$ & $\begin{array}{c}(1) \\
\text { Male } \\
\text { All } \\
\end{array}$ & $\begin{array}{c}(2) \\
\text { Female } \\
\text { All }\end{array}$ & $\begin{array}{c}(3) \\
\text { All } \\
\text { High }\end{array}$ & $\begin{array}{c}(4) \\
\text { All } \\
\text { Low }\end{array}$ & $\begin{array}{l}(5) \\
\text { Male } \\
\text { High }\end{array}$ & $\begin{array}{c}(6) \\
\text { Male } \\
\text { Low }\end{array}$ & $\begin{array}{c}(7) \\
\text { Female } \\
\text { High }\end{array}$ & $\begin{array}{c}(8)) \\
\text { Female } \\
\text { Low }\end{array}$ \\
\hline Age $>21$ During Term & $\begin{array}{c}-0.018^{* *} \\
(0.009)\end{array}$ & $\begin{array}{c}-0.032^{* * *} \\
(0.008)\end{array}$ & $\begin{array}{l}-0.008 \\
(0.008)\end{array}$ & $\begin{array}{c}-0.041^{* * *} \\
(0.008)\end{array}$ & $\begin{array}{c}0.001 \\
(0.012)\end{array}$ & $\begin{array}{c}-0.040^{* * *} \\
(0.013)\end{array}$ & $\begin{array}{l}-0.018 \\
(0.011)\end{array}$ & $\begin{array}{c}-0.044^{* * *} \\
(0.010)\end{array}$ \\
\hline Individual Fixed Effects & yes & yes & yes & yes & yes & yes & yes & yes \\
\hline Individual Trends & yes & yes & yes & yes & yes & yes & yes & yes \\
\hline Individual Quadratics & yes & yes & yes & yes & yes & yes & yes & yes \\
\hline Experience Controls & yes & yes & yes & yes & yes & yes & yes & yes \\
\hline Subject/Level/Term Controls & yes & yes & yes & yes & yes & yes & yes & yes \\
\hline Number of Students & 7452 & 9133 & 7979 & 8606 & 4018 & 3434 & 3961 & 5172 \\
\hline Observations & 254,412 & 307,164 & 275,424 & 286,152 & 139,495 & 114,917 & 135,929 & 171,235 \\
\hline
\end{tabular}

Notes: Same as Table 7. 
Table A3

Heterogeneity Across Gender and Financial Aid Eligibility Controlling for Individual Quadratic Trends

\begin{tabular}{|c|c|c|c|c|c|c|c|}
\hline $\begin{array}{l}\text { Gender: } \\
\text { Eligibility: }\end{array}$ & $\begin{array}{l}(1) \\
\text { All } \\
\text { All }\end{array}$ & $\begin{array}{c}(2) \\
\text { All } \\
\text { Above }\end{array}$ & $\begin{array}{c}(3) \\
\text { All } \\
\text { Below }\end{array}$ & $\begin{array}{c}(4) \\
\text { Male } \\
\text { Above } \\
\end{array}$ & $\begin{array}{c}(5) \\
\text { Male } \\
\text { Below } \\
\end{array}$ & $\begin{array}{c}(6) \\
\text { Female } \\
\text { Above }\end{array}$ & $\begin{array}{c}(7) \\
\text { Female } \\
\text { Below }\end{array}$ \\
\hline Age $>21$ During Term & $\begin{array}{c}-0.021^{* * *} \\
(0.007)\end{array}$ & $\begin{array}{c}-0.033^{* * *} \\
(0.010)\end{array}$ & $\begin{array}{l}-0.011 \\
(0.010)\end{array}$ & $\begin{array}{c}-0.026 \\
(0.016)\end{array}$ & $\begin{array}{c}0.003 \\
(0.015)\end{array}$ & $\begin{array}{c}-0.040 * * * \\
(0.013)\end{array}$ & $\begin{array}{l}-0.019 \\
(0.013)\end{array}$ \\
\hline Individual Fixed Effects & yes & yes & yes & yes & yes & yes & yes \\
\hline Individual Trends & yes & yes & yes & yes & yes & yes & yes \\
\hline Individual Quadratics & yes & yes & yes & yes & yes & yes & yes \\
\hline Experience Controls & yes & yes & yes & yes & yes & yes & yes \\
\hline Subject/Level/Term Controls & yes & yes & yes & yes & yes & yes & yes \\
\hline Number of Students & 11396 & 5705 & 5691 & 2378 & 2489 & 3327 & 3202 \\
\hline Observations & 390,451 & 192,767 & 197,684 & 80,934 & 87,267 & 111,833 & 110,417 \\
\hline
\end{tabular}

Notes: Same as Table 8. 